\title{
A comprehensive study on the effect of Ru addition to Pt electrodes for direct ethanol fuel cell
}

\author{
J DATTA*, S SINGH, S DAS ${ }^{\dagger}$ and N R BANDYOPADHYAY ${ }^{\dagger}$ \\ Department of Chemistry, ${ }^{\dagger}$ School of Materials Science and Engineering, \\ Bengal Engineering and Science University, Shibpur, Howrah 711 103, India
}

MS received 24 October 2008; revised 3 January 2009

\begin{abstract}
The electro-oxidation of ethanol was studied over nanosized Pt and different compositions of PtRu catalysts synthesized by the borohydride reduction method. Physicochemical characterizations of the catalyst material were made by X-ray diffraction (XRD), scanning electron microscopy (SEM) coupled with EDX analysis and transmission electron microscopy (TEM). XRD patterns showed that Ru induces a contraction of the Pt lattice. EDX provided the composition of binary catalysts while TEM images indicated uniform distribution of discrete nanoparticle of the catalysts with narrow range. The electro-catalytic activities of the materials towards ethanol oxidation were investigated through electrochemical techniques, viz. cyclic voltammetry (CV), potentiodynamic polarization, chronoamperometry (CA) and electrochemical impedance spectroscopy (EIS) at room temperature. The onset potential of ethanol electro-oxidation is lowered on bimetallic PtRu catalysts compared to that on $\mathrm{Pt}$ alone. Of the investigated catalyst compositions the one with the highest electrocatalytic activity was found to be $\mathrm{Pt}_{82} \mathrm{Ru}_{18}$. This enhancement towards ethanol oxidation is explained on the basis of a structural effect and modified bi-functional mechanism.
\end{abstract}

Keywords. Ethanol electrooxidation; PtRu alloy catalysts; electro catalytic activity; charge transfer resistance.

\section{Introduction}

Despite significant efforts to improve the power performance of pure hydrogen or reformate gas proton exchange membrane fuel cells (PEMFCs) using pure or reformed hydrogen, there are still many technological hurdles to overcome before its commercialization as stationary and vehicular power sources (O'Hayre et al 2006). This is due largely to difficulties in hydrogen supply infrastructure or fuel reforming technology associated with cleaning up of impurities such as $\mathrm{CO}$ and sulphur compounds.

In recent times the PEM-based direct alcohol fuel cell (DAFC) is receiving increased attention due to its much simpler peripheral units than those of the $\mathrm{H}_{2}-\mathrm{O}_{2}$ PEMFC systems, such as easy fuel delivery and storage, no need for reforming, humidification and stack cooling, and favourable power capability (Lamy et al 2001). Liquid fuels, such as methanol and ethanol, featuring higher volumetric and gravimetric energy densities and better energy efficiency, can be easily handled, stored and transported in comparison with gaseous fuels. During the past decade, direct methanol fuel cell (DMFC) has been widely investigated (Arico et al 1996; Wasmus and

*Author for correspondence (jayati_datta@rediffmail.com)
Kuver 1999; Hogarth and Ralph 2002) and considered as a possible power source for electric vehicles and other portable applications for the future. However, environmental concerns limit the use of methanol as a friendly fuel since it is volatile and relatively toxic than other small alcohols. On the other hand, ethanol is non toxic and has more energy density compared to methanol $(8.01 \mathrm{kWh} / \mathrm{kg}$ vs $6.09 \mathrm{kWh} / \mathrm{kg}$ ) (Lamy et al 2002) and can be easily produced in great quantity by fermentation of sugar-containing raw materials. Therefore, ethanol is more attractive than methanol for direct alcohol fuel cells operating at lower temperature.

In direct ethanol fuel cell, ethanol is electro-oxidized at the anode and oxygen is reduced at the cathode according to reactions (1) and (2), respectively to result in the generation of electricity and heat.

$$
\begin{gathered}
\text { Anode: } \mathrm{C}_{2} \mathrm{H}_{5} \mathrm{OH}+3 \mathrm{H}_{2} \mathrm{O} \rightarrow 2 \mathrm{CO}_{2}+12 \mathrm{H}^{+}+12 e \\
E^{0}=0.085 \mathrm{~V},
\end{gathered}
$$

Cathode: $3 \mathrm{O}_{2}+12 \mathrm{H}^{+}+12 e \rightarrow 6 \mathrm{H}_{2} \mathrm{O}$

$$
E^{0}=1.23 \mathrm{~V} \text {, }
$$

Overall: $\mathrm{C}_{2} \mathrm{H}_{5} \mathrm{OH}+3 \mathrm{O}_{2} \rightarrow 2 \mathrm{CO}_{2}+3 \mathrm{H}_{2} \mathrm{O}$

$$
E^{0}=1 \cdot 145 \mathrm{~V} \text {. }
$$


The desired reaction in direct ethanol fuel cells is the complete oxidation of ethanol to $\mathrm{CO}_{2}$ and water involving 12 electrons transfer per ethanol molecule. It is reported that ethanol electro-oxidation involves several pathways (Lamy et al 2001). The two major challenges viz. electrooxidative removal of CO-like intermediates and the scission of the $\mathrm{C}-\mathrm{C}$ bond still remain with the conversion process (Zhou et al 2004). Although attempts of increasing reaction temperature and adopting more active electrocatalysts can enhance the ethanol electrochemical reaction activity, the former is not, at least at present, the primary choice because the perfluorosulfonic-based polymer electrolyte membrane gets dehydrated at higher operation temperatures, resulting in the rise of reaction impedance and subsequent deterioration of fuel cell performance (Yang et al 2001).

It is well known that the structure, morphology and composition of the electrode material play a key role in the catalytic performance of alcohol electro-oxidation. When pure platinum electrode is used for ethanol electrooxidation many problems such as auto-inhibition or poisoning phenomena arise resulting in high overpotentials (Rightmire et al 1964; Iwasita and Pastor 1994). In order to increase the electrocatalytic activity of platinum towards ethanol oxidation, a second oxophilic metal like $\mathrm{Ru}$ (Laborade et al 1994; Volkmar et al 1996; Fujiwara et al 1999; Chen et al 2001; Song et al 2005), Rh (De Souza et al 2002), Mo (Oliveria Neto et al 2002), Os (Pacheo et al http://www.Arofe.army.mil) or Sn (Delime et al 1999; Vigier et al 2004) is usually introduced as alloying metal, thus promoting the electrocatalytic activity of pure platinum. PtRu nano-clusters have been the most investigated of fuel cell catalysts (Watanabe and Motoo 1975a; Janssen and Moolhuysen 1977). The superior performance of this catalyst relative to pure Pt has been explained in terms of either of two models: the bi-functional mechanism and the ligand effect. In the bi-functional mechanism model, $\mathrm{Ru}$ atom was recognized as a provider of oxygen-containing species for the $\mathrm{CO}$ oxidative removal as shown below:

$$
\mathrm{Ru}-\mathrm{OH}+\mathrm{Pt}-\mathrm{CO} \rightarrow \mathrm{Ru}+\mathrm{Pt}+\mathrm{CO}_{2}+\mathrm{H}^{+}+e^{-} .
$$

The ligand effect, on the other hand, known as the electronic model, was based on the modification of Pt electronic structure by the presence of $\mathrm{Ru}$ making $\mathrm{Pt}$ atoms less poisoned by $\mathrm{CO}$.

However, the ratio of the constituents in this binary catalyst has to be optimized because ethanol oxidation activity is known to be sensitive to the $\mathrm{Pt}$ : $\mathrm{Ru}$ content. This also includes varying the concentration of the surface oxide species. Detailed electrochemical and physical characterizations are therefore, required to understand the individual contribution of each of the constituents toward ethanol oxidation activity and in particular, the role of the surface oxide species. The mechanistic insights will form the basis for optimization of the catalyst composition for ethanol electro-oxidation.
In the present paper, we have studied the activity of chemically synthesized unsupported Pt and PtRu catalysts with different compositions towards the electro-oxidation of ethanol. The structure and morphology of the catalyst nanoparticles were determined by XRD, SEM and TEM. Electrochemical techniques like cyclic voltammetry, potentiodynamic polarization, chronoamperometry and electrochemical impedance spectroscopy (EIS) were used to investigate the catalytic activity towards electro-oxidation of ethanol.

\section{Experimental}

\subsection{Synthesis of unsupported catalysts}

Unsupported Pt and PtRu catalysts were synthesized in the powdered form by $\mathrm{NaBH}_{4}$ reduction of appropriate molar concentrations of $\mathrm{H}_{2} \mathrm{PtCl}_{6} \cdot x \mathrm{H}_{2} \mathrm{O}$ and $\mathrm{RuCl}_{3} \cdot 6 \mathrm{H}_{2} \mathrm{O}$ (Arora Matthey Ltd.). The mixtures were stirred for $1 \mathrm{~h}$ and subsequently appropriate quantities of $0.05 \mathrm{M}$ $\mathrm{NaBH}_{4}$ (Merck) solution were added, drop by drop, to the mixture with vigorous stirring for the complete reduction of $\mathrm{Pt}$ and/or $\mathrm{Ru}$ from their respective metal precursors. Subsequently the black colloidal mixtures were stirred for $30 \mathrm{~min}$ at room temperature. Finally the colloid was centrifuged, collected, washed with plenty of water and dried at $110^{\circ} \mathrm{C}$. In case of binary catalysts, the stoichiometry corresponded to $\mathrm{Pt}: \mathrm{Ru}$ molar ratios of $1: 1,5: 1$ and $10: 1$. Working electrodes were prepared using saw cut finish grade graphite plate (GLM, Graphite India Ltd) of thickness $\sim 2 \mathrm{~mm}$ as electrode substrate. A catalyst ink was prepared by mixing appropriate amount of catalysts, Nafion ionomer (5 wt \% solutions, Electrochem. Inc, USA) and 2-propanol (GR, Merck) and the mixture was sonicated. A fixed amount of this slurry was micropipetted out onto the graphite support $\left(0.65 \mathrm{~cm}^{2}\right)$ maintaining a constant catalyst loading of $0.5 \mathrm{mg} \mathrm{cm}^{-2}$.

\subsection{Physical characterization}

X-ray diffraction (XRD) patterns of the electrocatalysts were obtained in a SEIFERT 2000 diffractometer operating with $\mathrm{CuK}_{\alpha}$ radiation $(\lambda=0 \cdot 1540598 \mathrm{~nm})$ generated at $35 \mathrm{kV}$ and $30 \mathrm{~mA}$. Scans were done at $1^{\circ} \mathrm{min}^{-1}$ for $2 \theta$ values between 20 and 90 degrees. Scherrer equation was used for the determination of particle size from XRD. For this purpose, the (111) peak of the Pt face centred cubic $(f c c)$ structure was selected. The surface morphology of the electrocatalysts was investigated with a LEO S 430i scanning electron microscope at an accelerating potential of $20 \mathrm{kV}$. The chemical composition of the catalyst layers was determined by energy dispersive X-ray (EDX) using Link ISIS EDX detector (Oxford Instruments, UK) coupled with the scanning electron microscope. The morphology and the particle size distributions of PtRu catalysts were 
analysed by TEM observation. At first, the catalysts were ultrasonically dispersed in ethanol solution to obtain uniform catalyst ink and mounted onto a copper grid covered with carbon film. A JEOL JEM 2100 microscope, operating at $200 \mathrm{kV}$, was used for TEM observation.

\subsection{Electrochemical measurements}

Electrochemical measurements were carried out using cyclic voltammetry $(\mathrm{CV})$, potentiodynamic polarization studies, electrochemical impedance spectroscopy (EIS) and chronoamperometry with the help of a computer controlled potentiostat/galvanostat with PG STAT 12 and FRA modules (Eco Chemie BV, The Netherlands). A conventional H-type three-electrode cell consisting of catalyst coated graphite carbon with an area $0.65 \mathrm{~cm}^{2}$ as the working electrode, Pt foil as counter electrode and mercury-mercurous sulphate (MSE) as reference electrode $(0.68 \mathrm{~V}$ vs SHE) was used for electrochemical experiments. The electrolyte solution was de-aerated with pure nitrogen prior to each experiment. The $\mathrm{CV}$ experiments were performed in $0.5 \mathrm{M} \mathrm{H}_{2} \mathrm{SO}_{4}$ solution in the absence and presence of $1.0 \mathrm{M}$ ethanol at a scan rate of $50 \mathrm{mV} \mathrm{s}^{-1}$. Steady state potentiostatic data was recorded after polarization for $5 \mathrm{~min}$. The chronoamperometric experiments were studied at $-0 \cdot 1 \mathrm{~V}$ for $1 \mathrm{~h}$ duration. EIS measurements were performed in the frequency range $30 \mathrm{kHz}-$ $30 \mathrm{mHz}$ containing 40 data points. The amplitude of the a.c. signal was $5 \mathrm{mV}$.

\section{Results and discussion}

For the synthesis of binary catalysts, the borohydride method was adopted because of its procedural simplicity and proven effectiveness for synthesizing nanoparticles. The simultaneous reduction of metal salts has several intrinsic advantages, viz. assurance of molecular level mixing between the constituent metals and a predetermined stoichiometry based on the atomic composition in the precursor. For the present study the stoichiometry of the reduction reactions can be summarized as follows:

$$
\begin{aligned}
& 2 \mathrm{PtCl}_{6}^{2-}+\mathrm{BH}_{4}^{-}+4 \mathrm{H}_{2} \mathrm{O} \rightarrow 2 \mathrm{Pt}+\mathrm{B}(\mathrm{OH})_{4}^{-}+8 \mathrm{H}^{+}+12 \mathrm{Cl}^{-}, \\
& 8 \mathrm{Ru}^{3+}+3 \mathrm{BH}_{4}^{-}+12 \mathrm{H}_{2} \mathrm{O} \rightarrow 8 \mathrm{Ru}+3 \mathrm{~B}(\mathrm{OH})_{4}^{-}+24 \mathrm{H}^{+} .
\end{aligned}
$$

The relative atomic $\mathrm{Pt}: \mathrm{Ru}$ ratios of the chemically synthesized catalysts were determined by EDX analysis (table 1).

\subsection{SEM, EDX and TEM characterizations}

In order to investigate the morphology of the chemically synthesized unsupported Pt and PtRu catalysts, the samples were examined through scanning electron microscopy. A direct evaluation of the particle size is not possible for these Pt deposits which appear to be agglomerated for the SEM images. Figure 1 shows a typical SEM image of the $\mathrm{Pt}_{91} \mathrm{Ru}_{9}$ electrode surface. It shows catalyst particle sizes lie within a few nanometers and are in good agreement with the average particle size obtained from XRD measurement described in the following section. Figure 2 is a typical EDX spectrum of unsupported $\mathrm{Pt}_{91} \mathrm{Ru}_{9}$ catalyst. The EDX data show that the Pt:Ru atomic ratios of the obtained electrocatalysts were close to the nominal atomic ratios used during synthesis (table 1). HRTEM image of $\mathrm{Pt}_{82} \mathrm{Ru}_{18}$ catalyst particles, shown in figure 3, allowed direct measurement of the particle size distribution. In general, the PtRu alloy nanoparticles are spherical in shape and are $3-5 \mathrm{~nm}$ in size range. A representative selected area electron diffraction (SAED) pattern of the synthesized catalysts reveals the crystalline planes of the nanoparticles as shown in figure 4 . Further the concentric rings are indexed for the $f_{c c}$ structure of the Pt crystal lattice.

\section{$3.2 X$-ray diffraction (XRD)}

XRD provides the information on the bulk structure of the catalyst. Figure 5 shows the XRD patterns of unsupported Pt and PtRu catalysts. The XRD patterns of Pt can be indexed to the diffraction peaks of (111), (200), (220), (311) and (222) planes corresponding to a face centred cubic ( $f c c)$ structure (Liu et al 2005; Li et al 2007). All the PtRu catalysts prepared with different molar ratios of $\mathrm{Pt}$ : Ru displayed the diffraction peaks similar to those of Pt metal except that the $2 \theta$ values were shifted to slightly higher values. For instance, the $2 \theta$ of the (111) peaks of $\mathrm{Pt}$ and different molar ratios of PtRu such as (91:9), $(82: 18)$ and $(50: 50)$ are found at 39.829, 40.005, 40.030 and 40.084 , respectively (figure 6). Such evidence

Table 1. Ratio of $\mathrm{Pt}$ and $\mathrm{Ru}$ precursor salts used in synthesis and that obtained on

\begin{tabular}{|c|c|c|c|c|c|}
\hline \multirow[b]{2}{*}{$\mathrm{H}_{2} \mathrm{PtCl}_{6}(\mathrm{M})$} & \multirow[b]{2}{*}{$\mathrm{RuCl}_{3}(\mathrm{M})$} & $\% \mathrm{Pt}$ & $\% \mathrm{Ru}$ & \multirow{2}{*}{$\begin{array}{c}\mathrm{Pt} / \mathrm{Ru} \\
\text { (solution) }\end{array}$} & \multirow{2}{*}{$\underset{\text { (catalyst) }}{\mathrm{Pt} / \mathrm{Ru}}$} \\
\hline & & \multicolumn{2}{|c|}{ from EDX } & & \\
\hline $2 \cdot 0 \times 10^{-2}$ & $2.0 \times 10^{-3}$ & $90 \cdot 9$ & $9 \cdot 1$ & 10 & $9 \cdot 9$ \\
\hline $2.0 \times 10^{-2}$ & $4.0 \times 10^{-3}$ & $81 \cdot 6$ & $18 \cdot 4$ & 5 & $4 \cdot 4$ \\
\hline $2 \cdot 0 \times 10^{-2}$ & $2 \cdot 0 \times 10^{-2}$ & $50 \cdot 3$ & 49.7 & 1 & $1 \cdot 01$ \\
\hline
\end{tabular}
the PtRu catalysts as determined by EDX analysis. 
accounts for the formation of PtRu alloy in the catalysts. However, the peaks associated with a typical hexagonal closed packed $(h c p)$ structure of pure ruthenium or ruthenium oxide phase did not appear in the XRD pattern of PtRu catalysts (Colmati et al 2002; Spinace et al 2004). Despite the absence of such peaks, some amount of metallic $\mathrm{Ru}$ and its oxides in the amorphous state may always exist in the PtRu catalyst. The lattice parameter (a) values of the Pt and PtRu alloy based nanocatalysts with different molar ratios of $\mathrm{Pt}$ : Ru was calculated from broadening of the (111) diffraction peak and listed in table 2. Consistent with the literature data, the $\mathrm{Pt}_{50} \mathrm{Ru}_{50}$ catalyst has a much smaller lattice parameter $(a=$ $3.8916 \mathrm{~nm}$ ) (Colmati et al 2007) and this may indicate that the addition of the secondary metal Ru has a considerable influence on the crystal structure of Pt catalyst (Li et al 2007). This can be explained by its different atomic size as against that of Pt element $\left(R_{\mathrm{Pt}}=1.39 \AA\right.$ and $R_{\mathrm{Ru}}=1.34 \AA$ ). However, the lattice parameter of $3.9155 \AA$ for the prepared Pt catalyst is in good agreement with the literature value of $3.923 \AA$ for pure $\mathrm{Pt}$ (JCPDS 04-0802). The average crystallite size and lattice parameters for the PtRu alloys prepared with different molar ratios of $\mathrm{Pt}: \mathrm{Ru}$ was calculated from broadening of the (111) diffraction peak using Scherrer equation and is listed in table 2. The composition of the PtRu catalysts was further determined with the help of Vegard's law, from the shift of Pt diffraction peaks, or the variation of the lattice parameter from the XRD patterns. From literature data (Chu and Gilman 1996), a linear relationship of the lattice parameter and the alloyed $\mathrm{Ru}$ atomic fraction $(<0.7)$ has been proposed:

$$
a(\mathrm{Pt}-\mathrm{M})=a(\mathrm{Pt})-k x(\mathrm{Ru}),
$$

where $a(\mathrm{Pt})$ and $a(\mathrm{Pt}-\mathrm{M})$ represent the lattice parameter of Pt and the Pt-Ru alloyed catalyst, respectively. The

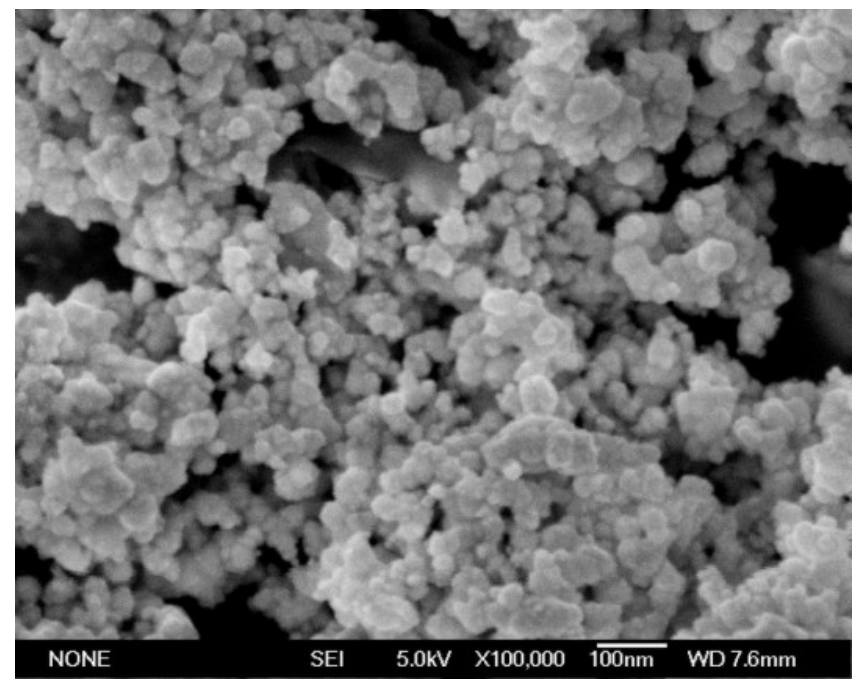

Figure 1. SEM images of chemically synthesized unsupported $\mathrm{Pt}_{91} \mathrm{Ru}_{9}$. value of constant $k=0 \cdot 124 \AA$ was taken from literature (Li et al 2007). According to this equation, the atomic content of alloyed $\mathrm{Ru}[x(\mathrm{Ru})]$ in our PtRu samples like $\mathrm{Pt}_{91} \mathrm{Ru}_{9}, \mathrm{Pt}_{82} \mathrm{Ru}_{18}$ and $\mathrm{Pt}_{50} \mathrm{Ru}_{50}$ are $0.1323,0.1512$ and $0 \cdot 1918$, respectively which are summarized in table 2 . Figure 7 is a plot of the evaluated lattice parameters as a function of at. \% Pt (as obtained from EDX) in PtRu catalysts.

\subsection{Cyclic voltammetric study in base electrolyte}

Figures 8(a)-(c) show a comparison of the cyclic voltammograms of $\mathrm{Pt}$ and $\mathrm{PtRu}$ catalysts of different stoichiometries in $0.5 \mathrm{M} \mathrm{H}_{2} \mathrm{SO}_{4}$. The upper potential limit was restricted to $0.2 \mathrm{~V}$ vs MSE because beyond this potential $\mathrm{Ru}$ dissolutes from the electrode surface during multiple scanning. With increasing $\mathrm{Ru}$ content in the binary catalysts the current-potential peaks in the hydrogen-adsorption region become broader and less defined than on pure Pt. Following the hydrogen region, the double layer region for the Pt electrode is narrow and featureless. The current slowly rises at $0 \cdot 10 \mathrm{~V}$ potential indicating the formation of surface oxides. In contrast, the current response in the double layer region of the $\mathrm{PtRu}$ electrodes becomes progressively broader with increasing Ru. This can be accounted for by the reversible formation and reduction of surface $\mathrm{Ru}$ oxides in this potential region, the amount of which increases with the $\mathrm{Ru}$ content of the catalysts. The position of the oxide reduction peak in the negative going sweep shifts to lower potentials for electrodes with higher $\mathrm{Ru}$ content. This agrees well with the results of McNicol and Short (1978), Mahmood et al (1981) and Frelink et al's (1995) findings although they had adopted a different synthetic method for PtRu alloys and PtRu codeposited electrodes, respectively. The major change in the voltammetric response due to the incorporation of $\mathrm{Ru}$ on the Pt surface is the increasing double layer currents over that of Pt indicating the adsorption of oxygen-like species at progressively more negative potentials as compared to Pt itself.

\subsection{Cyclic voltammograms of ethanol electro oxidation}

Figure 9 compares the ethanol oxidation behaviour over Pt and PtRu catalysts. A higher efficiency for ethanol oxidation at more negative potentials i.e. at lower overpotentials, is obtained with the PtRu catalysts. In this respect, $\mathrm{Pt}_{82} \mathrm{Ru}_{18}$ displays the highest activity amongst all catalyst formulations employed in this study. The enhancement of activity of these binary catalysts towards ethanol electro-oxidation can be related to their superior $\mathrm{CO}$ tolerance. The effect of adding $\mathrm{Ru}$ on ethanol oxidation is explained by the well known bifunctional mechanism (Watanabe and Motoo 1975b; Iwasita 2002): 


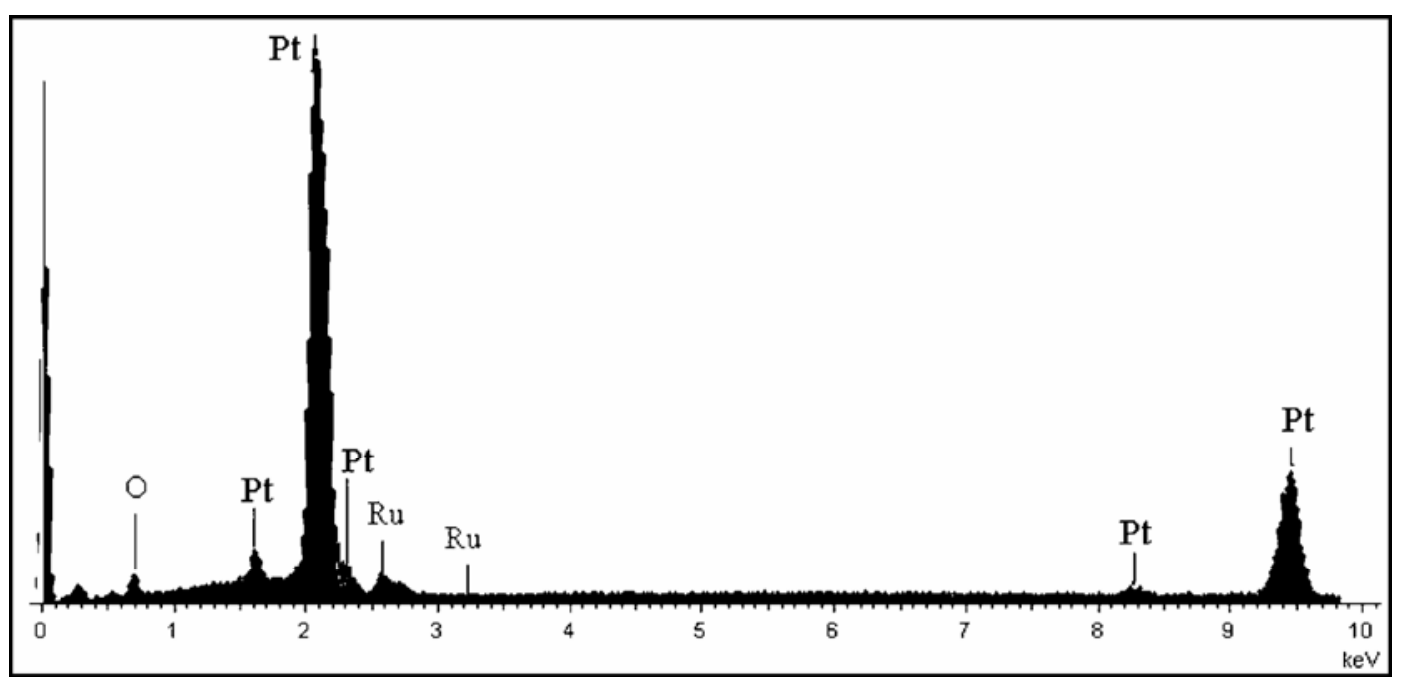

Figure 2. EDX spectrum of the unsupported $\mathrm{Pt}_{91} \mathrm{Ru}_{9}$ catalyst.

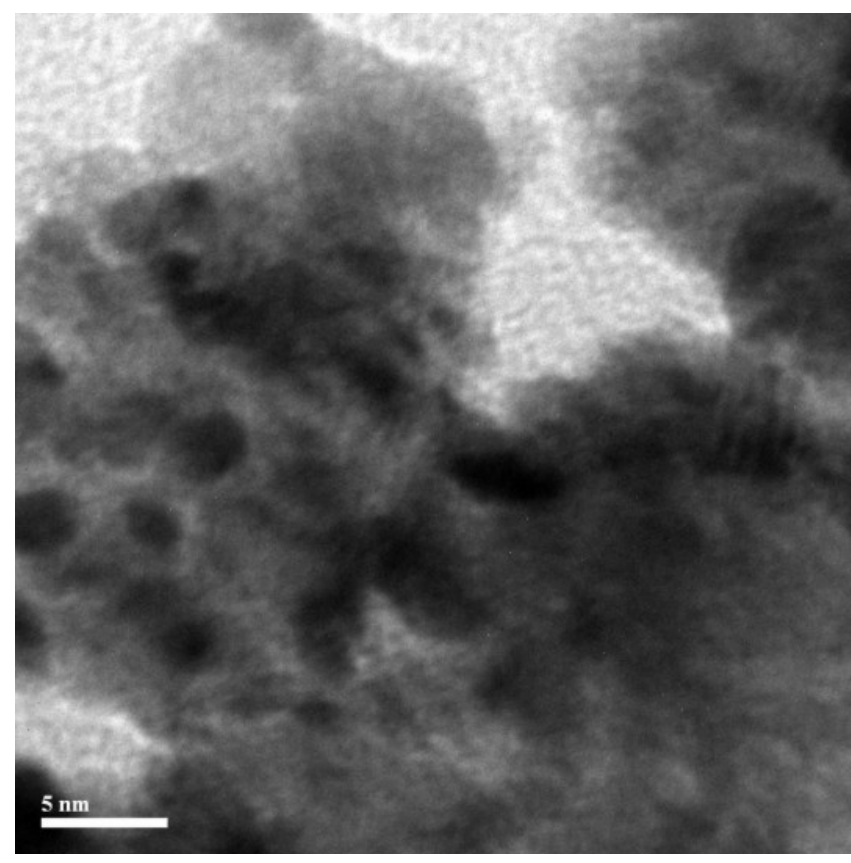

Figure 3. HRTEM image of the unsupported $\mathrm{Pt}_{82} \mathrm{Ru}_{18}$.

$$
\begin{aligned}
& \mathrm{Pt}+\mathrm{CO} \rightarrow \mathrm{Pt}-\mathrm{CO}_{\mathrm{ad}}, \\
& \mathrm{Ru}+\mathrm{H}_{2} \mathrm{O} \rightarrow \mathrm{Ru}-\mathrm{OH}_{\mathrm{ad}}+\mathrm{H}^{+}+e^{-}, \\
& \mathrm{Pt}-\mathrm{CO}_{\mathrm{ad}}+\mathrm{Ru}-\mathrm{OH}_{\mathrm{ad}} \rightarrow \mathrm{CO}_{2}+\mathrm{H}^{+}+e^{-} .
\end{aligned}
$$

Ethanol is adsorbed on the Pt surface and is oxidized to $\mathrm{CO}$. Although $\mathrm{Ru}$ itself has been found to be inactive for ethanol oxidation, $\mathrm{Ru}$ oxidatively decomposes water and $\mathrm{OH}$ is adsorbed on the $\mathrm{Ru}$ surface. Thus, $\mathrm{Ru}$ supplies oxygen species for $\mathrm{CO}$ oxidation and promotes ethanol oxidation. The $\mathrm{OH}$ adsorption on the $\mathrm{Ru}$ surface commences at $-0.35 \mathrm{~V}$, which shifts the onset potential of ethanol oxidation in the negative direction. However, this lowering of the onset potential is progressively reduced

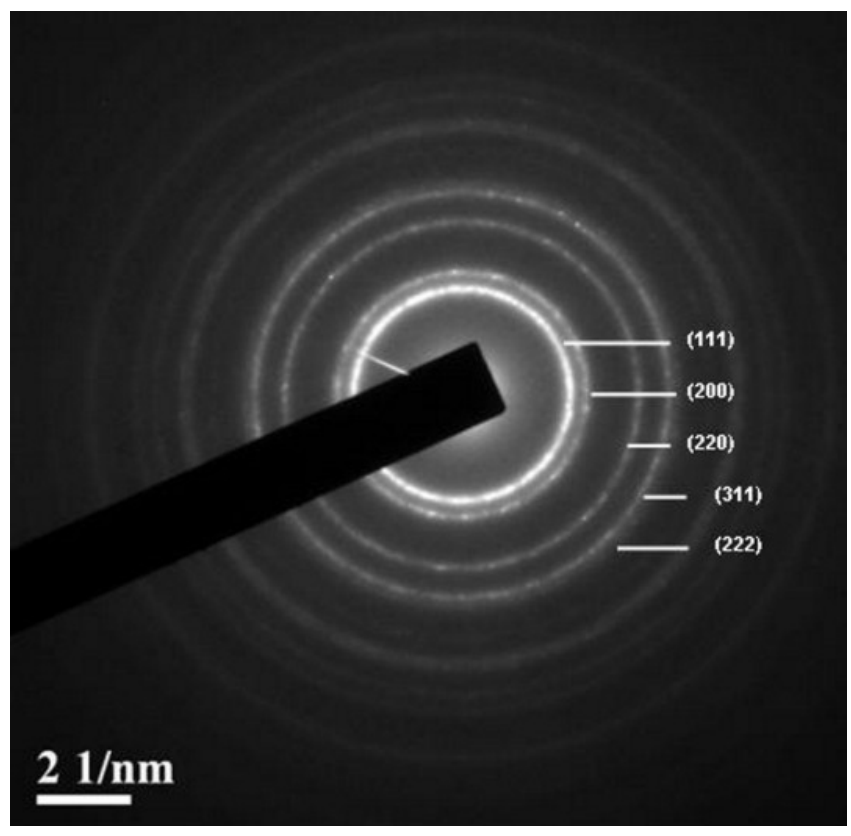

Figure 4. Selected area electron diffraction (SAED) pattern of $\mathrm{Pt}_{82} \mathrm{Ru}_{18}$ catalyst. The rings are indexed for an $f c c$ crystal structure.

on moving towards higher $\mathrm{Ru}$ content, until for the $\mathrm{Pt}_{50} \mathrm{Ru}_{50}$ catalyst composition the current response almost merges with that of $\mathrm{Pt}$ in the -0.25 to $0.1 \mathrm{~V}$ potential window. The lowering of the oxidation current with increasing $\mathrm{Ru}$ content is probably a manifestation of the drastic reduction in the number of ethanol adsorption sites on the $\mathrm{Pt}_{50} \mathrm{Ru}_{50}$ catalyst surface as compared to $\mathrm{Pt}$ alone.

The onset potential for ethanol oxidation is an important parameter for judging the activity of Pt-based electrocatalysts operating through a bifunctional mechanism. From figure 9(a) it is quite clear that in the hydride 
Table 2. Average crystallite size and lattice parameter of the Pt and PtRu catalysts compositions obtained from XRD measurements.

\begin{tabular}{lccccc}
\hline Catalysts & $2 \theta$ (degrees) & $\begin{array}{c}\text { Full width at half } \\
\text { maxima }(\AA)\end{array}$ & $\begin{array}{c}\text { Average crystallite } \\
\text { size }(\mathrm{nm})^{\mathrm{a}}\end{array}$ & $\begin{array}{c}\text { Lattice } \\
\text { parameter }(\AA)^{\mathrm{b}}\end{array}$ & $X_{\mathrm{Ru}}{ }^{\mathrm{c}}$ \\
\hline $\mathrm{Pt}$ & 39.829 & 2.8431 & 2.97 & 3.9155 & - \\
$\mathrm{Pt}_{91} \mathrm{Ru}_{9}$ & $40 \cdot 005$ & 1.4116 & 5.99 & 3.8990 & $0 \cdot 1323$ \\
$\mathrm{Pt}_{83} \mathrm{Ru}_{17}$ & 40.030 & 1.6738 & 5.05 & 3.8966 & $0 \cdot 1512$ \\
$\mathrm{Pt}_{50} \mathrm{Ru}_{50}$ & 40.084 & 3.7301 & $2 \cdot 3$ & 3.8916 & $0 \cdot 1918$ \\
\hline
\end{tabular}

${ }^{a}$ Calculated from Pt (111) peak position according to Scherrer formula; ${ }^{b}$ calculated from $\mathrm{Pt}(111)$ peak according to Bragg formula; " mole fraction of $\mathrm{Ru}$ in the alloyed state $\left(X_{\mathrm{Ru}}\right)$ calculated from Vegard's law

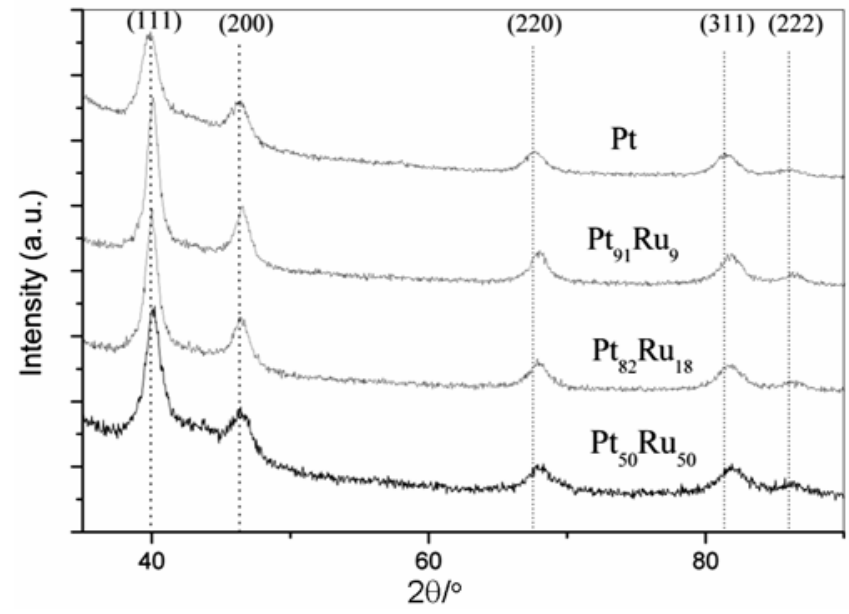

Figure 5. X-ray diffraction patterns of platinum and platinum-ruthenium catalysts.

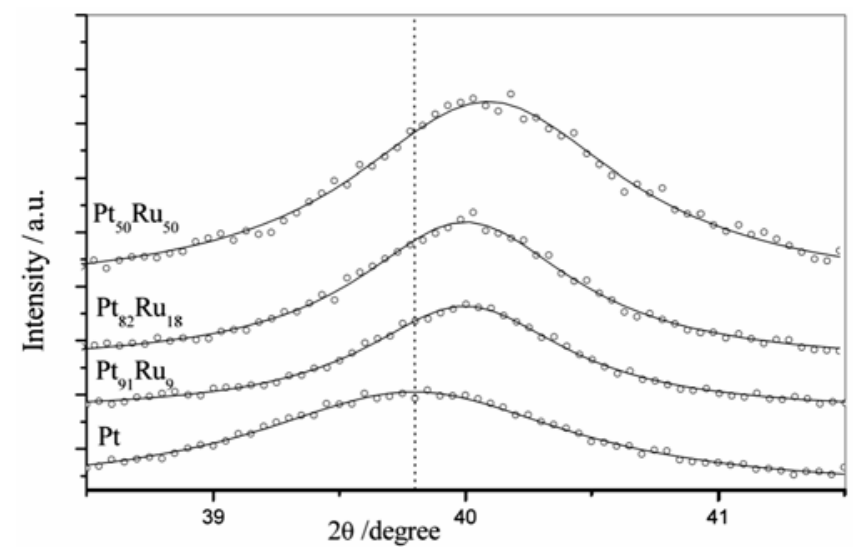

Figure 6. (111) diffractions of Pt and PtRu electrocatalysts.

region ethanol adsorption current of $\mathrm{Pt}_{82} \mathrm{Ru}_{18}$ is higher in comparison to other catalysts. The oxidation current of $\mathrm{Pt}_{82} \mathrm{Ru}_{18}$ commences sharply at a negative potential of $-0 \cdot 4 \mathrm{~V}$ whereas, the other catalysts suffer a decreasing current trend at the same potential and the oxide currents start at a much higher potential than that for $\mathrm{Pt}_{82} \mathrm{Ru}_{18}$.

\subsection{Potentiodynamic polarization study}

The beneficial effect of $\mathrm{Ru}$ towards electro-oxidation of ethanol is further exemplified by a comparison of the

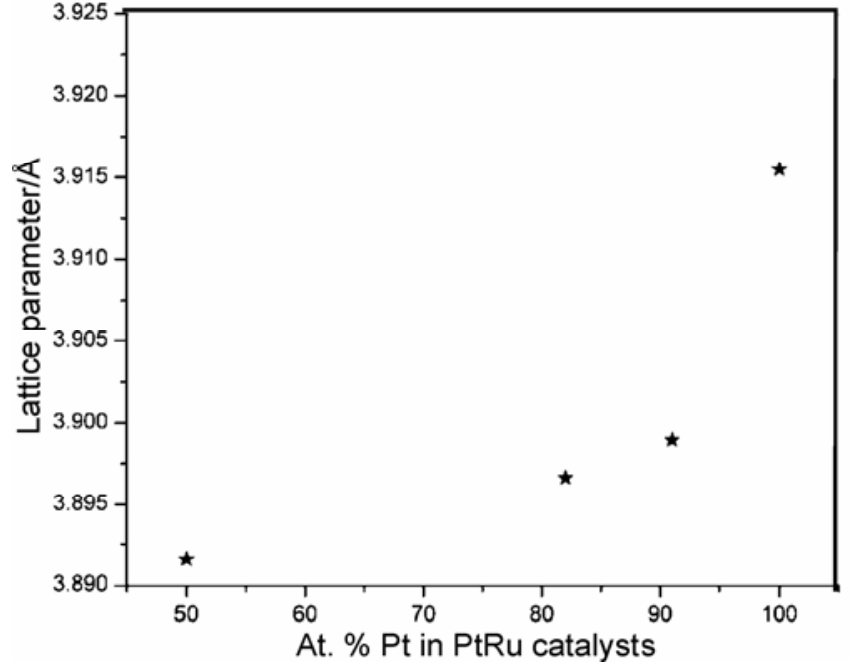

Figure 7. Lattice parameter as function of at.\% Pt (as obtained from EDX) in PtRu catalysts

polarization current densities. Figure 10 shows the current-potential behaviour during potentiodynamic polarization studies at a scan rate of $1 \mathrm{mV} \mathrm{s}^{-1}$ of ethanol electro-oxidation on Pt and PtRu electrodes of different compositions. At a potential of $-0 \cdot 2 \mathrm{~V}$, there is a ten-fold increase in current density of $\mathrm{Pt}_{82} \mathrm{Ru}_{18}$ compared to Pt. More significantly a negative shift of about $150 \mathrm{mV}$ is observed at $\mathrm{Pt}_{82} \mathrm{Ru}_{18}$ compared to Pt. The $\mathrm{Pt}_{82} \mathrm{Ru}_{18}$ alloy electrode shows the best polarization behaviour over the entire potential range studied. The higher electrocatalytic activity for the binary PtRu deposits is easily explained on the basis of the promoting effect of $\mathrm{Ru}$ for the electrooxidation of alcohols in acid medium.

\subsection{Chronoamperometric studies}

In order to ascertain the long-term stability of the electrodes, chronoamperograms were also recorded at $-0 \cdot 1 \mathrm{~V}$ for $1 \mathrm{~h}$. In all the chronoamperometric curves (figure 11), there is a sharp initial current drop followed by a slower decay. As can be seen, the polarization current recorded for the $\mathrm{Pt}_{82} \mathrm{Ru}_{18}$ electrode, even for a span of $1 \mathrm{~h}$, produces the highest oxidation current which is almost five 
times higher than that obtained with Pt. Taking into account that ensembles of Pt surface atoms are required for the adsorption of ethanol on $\mathrm{Pt}$ and that ethanol does not adsorb on $\mathrm{Ru}$, it follows that the promoter atoms should be present in low amounts. It may be said that
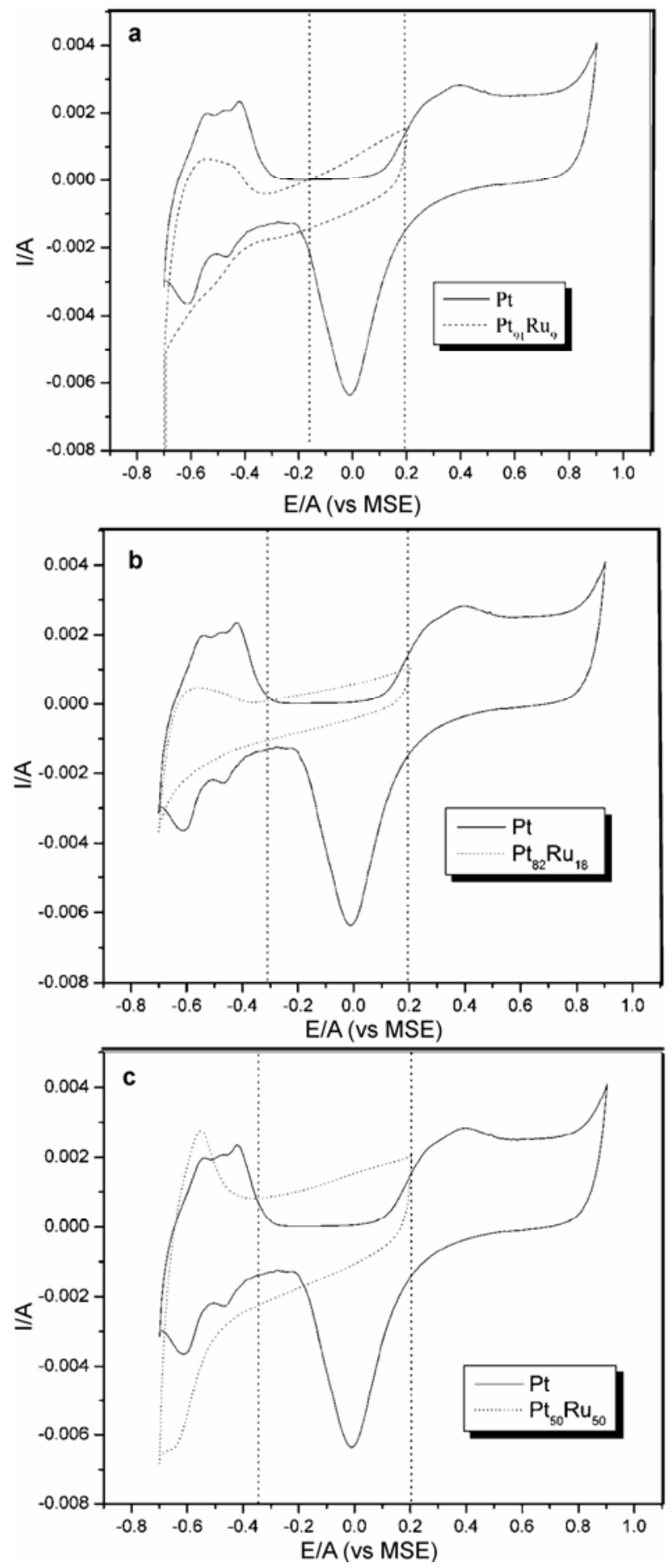

Figure 8. Comparison of cyclic voltammograms in $0.5 \mathrm{M} \mathrm{H}_{2} \mathrm{SO}_{4}$ of $\mathrm{Pt}$ with a. $\mathrm{Pt}_{91} \mathrm{Ru}_{9}\left(\right.$ scan rate $\left.=50 \mathrm{mV} \mathrm{s}^{-1}\right)$, b. $\mathrm{Pt}_{82} \mathrm{Ru}_{18}\left(\right.$ scan rate $\left.=50 \mathrm{mV} \mathrm{s}^{-1}\right)$ and c. $\mathrm{Pt}_{50} \mathrm{Ru}_{50}$ (scan rate $=$ $50 \mathrm{mV} \mathrm{s}^{-1}$ ).

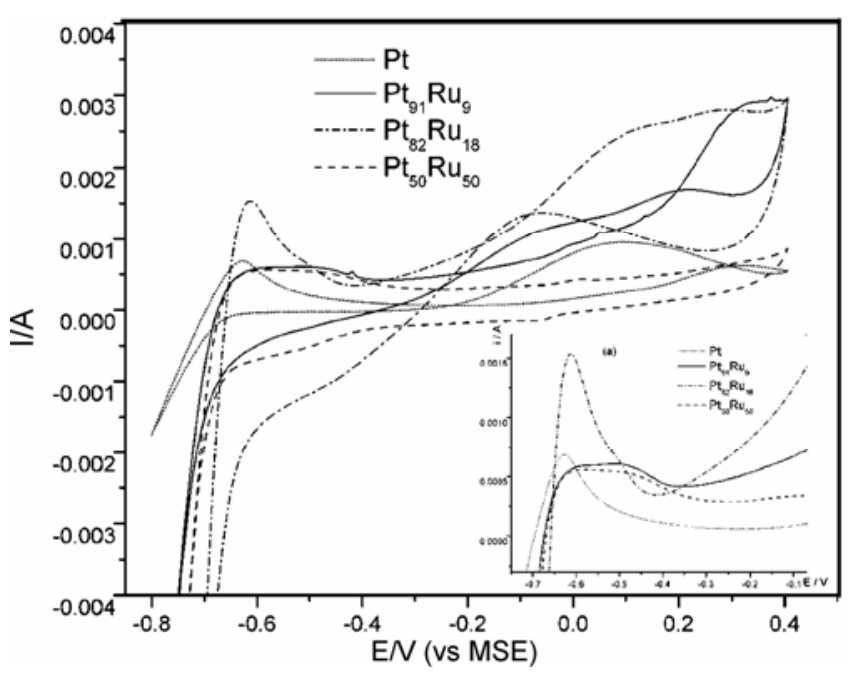

Figure 9. Comparison of cyclic voltammograms in $1 \mathrm{M} \mathrm{EtOH}$ of $\mathrm{Pt}$ with different compositions of PtRu (scan rate $\left.=50 \mathrm{mV} \mathrm{s}^{-1}\right)$.

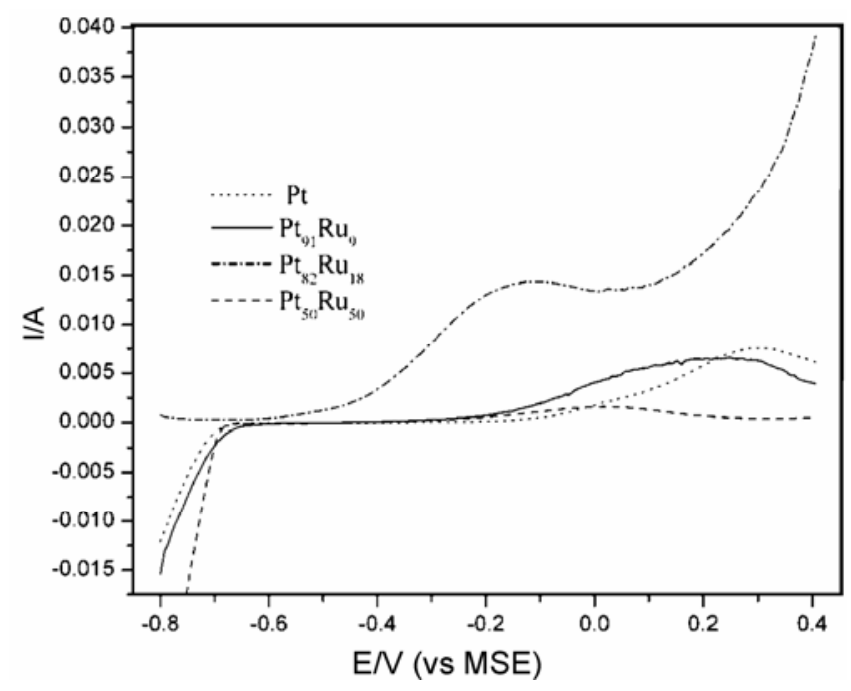

Figure 10. Potentiodynamic polarization plots obtained in $1.0 \mathrm{M}$ ethanol and $0.5 \mathrm{M} \mathrm{H}_{2} \mathrm{SO}_{4}$ at a scan rate of $1 \mathrm{mV} \mathrm{s}^{-1}$.

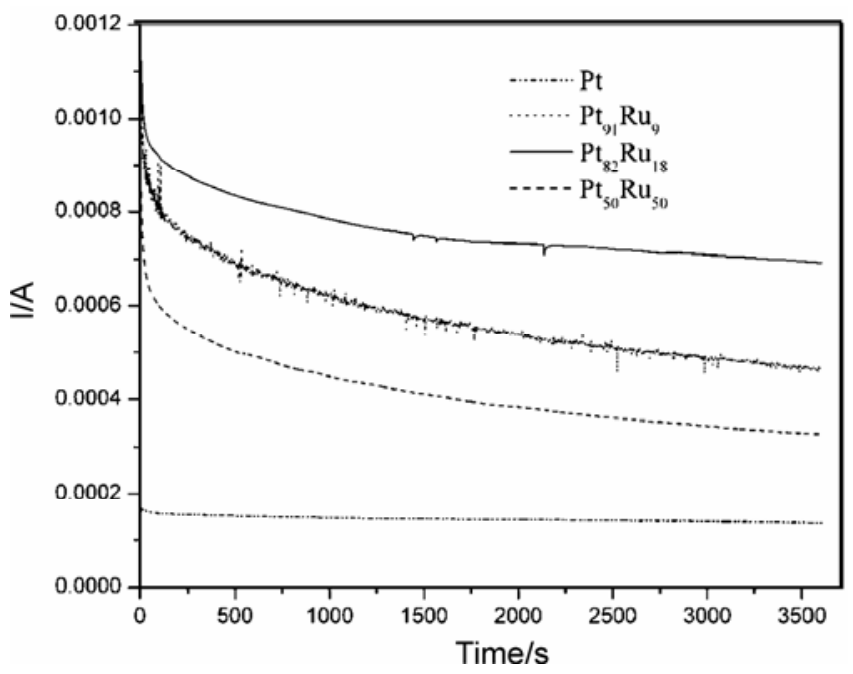

Figure 11. Chronoamperograms recorded at $-0 \cdot 1 \mathrm{~V}$ for $\mathrm{Pt}$ and PtRu electrocatalysts in $0.5 \mathrm{M} \mathrm{H}_{2} \mathrm{SO}_{4}+1.0 \mathrm{M} \mathrm{EtOH}$. 
Table 3. Values of the electrical elements obtained by fitting the impedance data at $-0 \cdot 1 \mathrm{~V}$ with the equivalent circuits shown in figures $15 \mathrm{a}$ and $\mathrm{b}$.

\begin{tabular}{lcccccc}
\hline Catalyst & $R_{\mathrm{s}}(\mathrm{ohm})$ & $\mathrm{CPE} \times 10^{3}$ & $R_{\mathrm{ct}}(\mathrm{ohm})$ & $\mathrm{C}_{\mathrm{P}}(\mathrm{mF})$ & $R_{\infty}(\mathrm{ohm})$ & $\begin{array}{c}\text { Frequency of } \\
-\phi_{\max }(\mathrm{mHz})\end{array}$ \\
\hline $\mathrm{Pt}$ & 14.62 & $2 \cdot 303$ & 8100 & - & - & $205 \cdot 4$ \\
$\mathrm{Pt}_{91} \mathrm{Ru}_{9}$ & 3.90 & $2 \cdot 510$ & $431 \cdot 3$ & $2 \cdot 98$ & 416 & $2376 \cdot 0$ \\
$\mathrm{Pt}_{82} \mathrm{Ru}_{18}$ & $1 \cdot 85$ & 3.420 & $215 \cdot 9$ & $7 \cdot 11$ & $26 \cdot 33$ & $6790 \cdot 0$ \\
$\mathrm{Pt}_{50} \mathrm{Ru}_{50}$ & 9.54 & $2 \cdot 295$ & 8030 & $3 \cdot 26$ & 120 & $991 \cdot 0$ \\
\hline
\end{tabular}

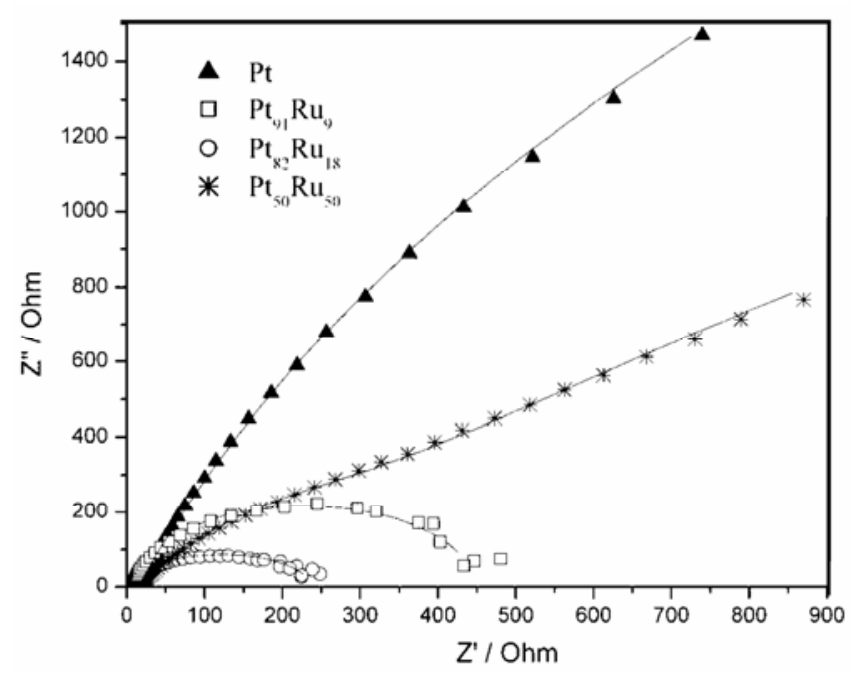

Figure 12. Nyquist plots (equivalent circuit fitted) of ethanol oxidation at a potential of $-0 \cdot 10 \mathrm{~V}$.

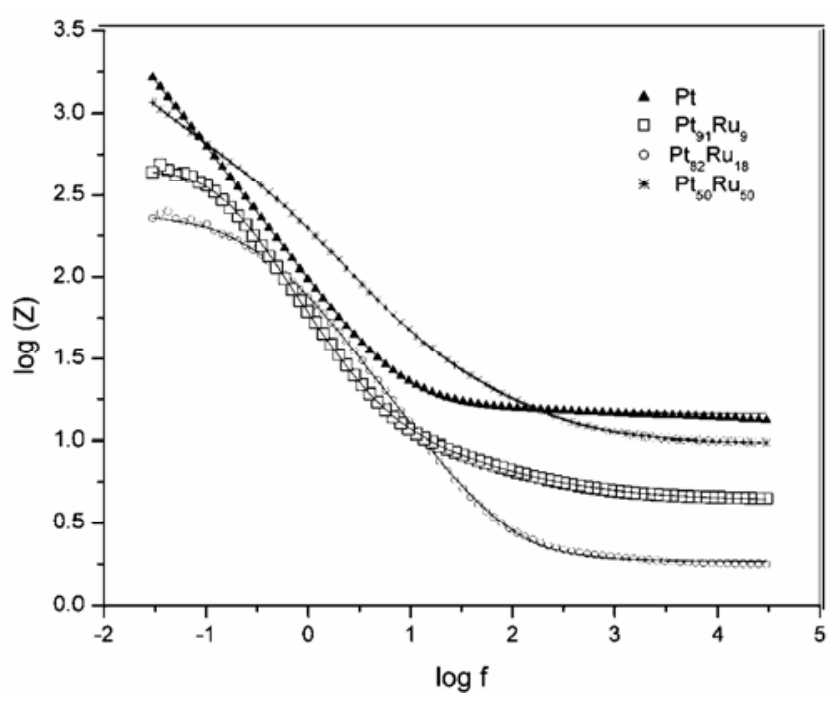

Figure 13. Bode plot-frequency vs total impedance of unsupported $\mathrm{Pt}$ and $\mathrm{PtRu}$ at different compositions.

sufficient number of Pt sites enabling the reaction to proceed to the $\mathrm{CO}_{\text {ads }}$ stage is the prerequisite for $\mathrm{Ru}$ to act via oxygen transfer. This is tenable with our results for an activity maximum with $\sim 18$ at. $\%$ Ru catalyst.

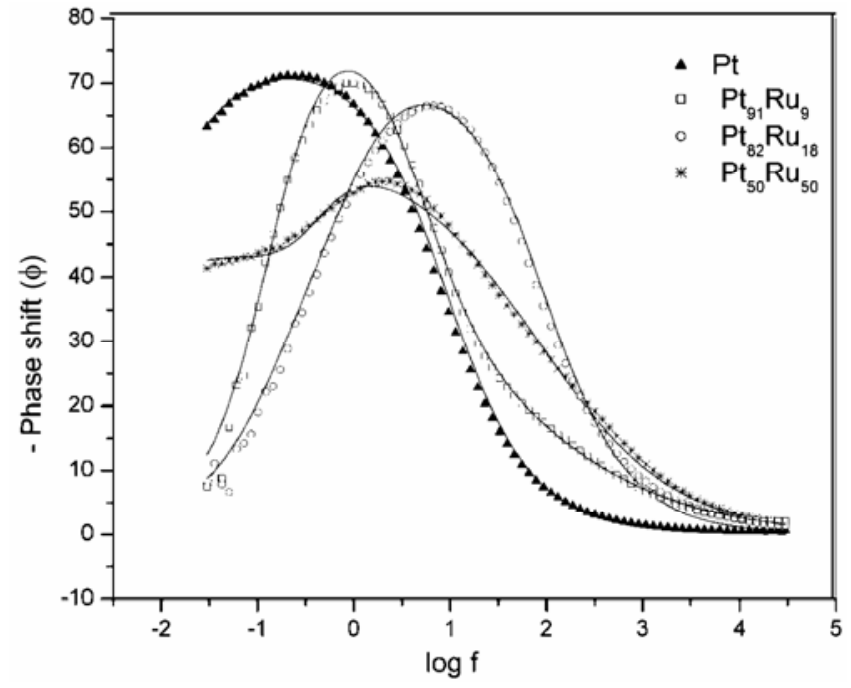

Figure 14. Bode plot-frequency vs phase angle of unsupported $\mathrm{Pt}$ and $\mathrm{PtRu}$ at different compositions.

\subsection{Electrochemical impedance spectroscopy}

Nyquist plots obtained for ethanol oxidation on the unsupported $\mathrm{Pt}$ and $\mathrm{PtRu}$ electrodes in $1 \mathrm{M}$ ethanol and $0.5 \mathrm{M} \mathrm{H}_{2} \mathrm{SO}_{4}$ at $-0.1 \mathrm{~V}$ vs MSE are presented in figure 12. The complex-plane impedance of unsupported $\mathrm{Pt}$ shows almost a line with an initial slope close to $90^{\circ}$ along the imaginary axis $\left(Z^{\prime \prime}\right)$, characteristic of an ideally polarizable electrode as in an electric double-layer capacitor. A slight deviation from the straight line is observed at low frequency $(<0 \cdot 1 \mathrm{~Hz})$, which may be an indication of the commencement of the dissociative ethanol adsorption. The complex-plane plots for $\mathrm{Pt}_{91} \mathrm{Ru}_{9}$ and $\mathrm{Pt}_{82} \mathrm{Ru}_{18}$ are evidenced by the formation of arc which indicates the presence of a resistive component. The transition from capacitive behaviour to resistive behaviour is more clearly evident in the corresponding Bode plots (figures 13 and 14). The transformation behaviour can be distinguished by a characteristic frequency where the $-\Phi$ value exhibits a maximum i.e. the deviation from the $-90^{\circ}$ phase angle (Sugimoto et al 2005). The phase angle is almost constant down to $10 \mathrm{MHz}$ for unsupported Pt. Therefore, the electrode reaction is dominated by the electric double-layer capacitance and the electrocatalysis is small within the frequency range studied. A maximum appears in the $-\Phi$ 
value in the Bode plots for Pt below $-0.07 \mathrm{~Hz}$ and the characteristic frequency increases to higher frequency in the order $\mathrm{Pt}<\mathrm{Pt}_{91} \mathrm{Ru}_{9}<\mathrm{Pt}_{50} \mathrm{Ru}_{50}<\mathrm{Pt}_{82} \mathrm{Ru}_{18}$ which implies that predominance of the resistive behaviour is translated to increased electroactivity (as shown in table 3). Based on these observations, it may be stated that an optimum $\mathrm{Ru}$ content in binary PtRu catalysts for ethanol oxidation is reached at $18 \% \mathrm{Ru}$ levels. The impedance data of unsupported Pt were fitted using the equivalent circuit shown in figure 15(a), where a parallel constant-phase element $(\mathrm{CPE})$-resistor $\left(R_{\mathrm{ct}}\right)$ combination was added in series of solution resistance (Rs). Here, CPE and $R_{\mathrm{ct}}$ are the frequency-dependent capacitance and charge-transfer resistance, respectively at the outermost surface of the electrode. A capacitor $\left(C_{\mathrm{P}}\right)$ was also used for the electric double-layer capacitance to account for the porous PtRu. The fit based on the modified equivalent circuit (figure 15(b)) agrees well with the experimental data throughout the whole frequency range studied. The value of capacitance was in the range $2-8 \mathrm{mF}$ (as shown in table 3 ) which is a reasonable value for the electrical double-layer capacitance. The reaction resistance of $\mathrm{CH}_{3} \mathrm{CH}_{2} \mathrm{OH}$ to $\mathrm{CO}_{\mathrm{ad}}\left(R_{\infty}\right)$ which was combined in parallel with capacitor $\left(C_{\mathrm{P}}\right)$ decreases with increase of $\mathrm{Ru}$ content with a minimum value for $\mathrm{Pt}_{82} \mathrm{Ru}_{18}$ electrode as shown in table 3 . The values reflect that there should be an optimum ratio of $\mathrm{Pt}$ to $\mathrm{Ru}$ sites for both the dissociative adsorption of ethanol as well as the subsequent $\mathrm{CO}$ oxidation step at lower overpotential. This is best satisfied by the $\mathrm{Pt}_{82} \mathrm{Ru}_{18}$ electrode.

\section{Conclusions}

This work deals with the study of electro-oxidation of ethanol on Pt based alloy catalysts containing different atomic percentages of $\mathrm{Ru}$ which were synthesized by borohydride reduction method. Based on the results obtained from different electrochemical techniques like $\mathrm{CV}$, polarization studies, EIS and chronoamperometry employed for the study of electrocatalytic behaviour of different catalysts, the $\mathrm{Pt}_{82} \mathrm{Ru}_{18}$ alloy was identified as the best composition in promoting ethanol oxidation in acid medium. This is ascribed to the optimum number of $\mathrm{Ru}$ sites available in the matrix which is required for the oxi-

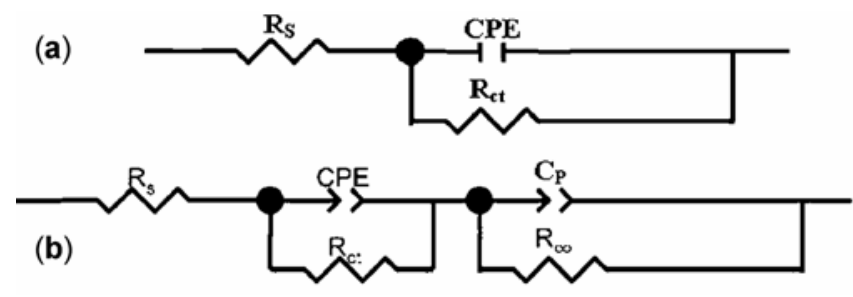

Figure 15. (a) Equivalent circuit for modeling the impedance data of Pt and (b) equivalent circuit for modeling the impedance data of PtRu catalysts. dation of adsorbed $\mathrm{CO}$ species subsequent to the dissociative adsorption of ethanol at Pt centres. At substantially higher Ru concentration, ethanol adsorption is significantly inhibited as the number of Pt sites available for the purpose is not sufficient. On the other hand, at low Ru concentration, there are possibly not enough Ru sites to effectively oxidize the adsorbed $\mathrm{CO}$ and catalytic activity remains low.

\section{Acknowledgement}

We gratefully acknowledge the Defence Research and Development Organization (DRDO), New Delhi, for financial support.

\section{References}

Arico A S, Creti P, Kim H, Mantegna R, Giordano N and Antonucci V 1996 J. Electrochem. Soc. 1433950

Chen G L, Sun S G, Chen S P and Zhou Z Y 2001 Chinese Appl. Chem. 18432

Chu D and Gilman S 1996 J. Electrochem. Soc. 1431686

Colmati F, Lizacano-Valbuena W H, Camara G A, Ticianelli E A and Gonzalez E R 2002 J. Braz. Chem. Soc. 13474

Colmati F, Antolini E and Gonzalez E R 2007 J. Electrochem. Soc. 154 B39

Delime F, Léger J -M and Lamy C 1999 J. Appl. Electrochem. 291249

De Souza J P I, Queiroz S L, Bergmaski K, Gonzalez E R and Nart F C 2002 J. Phys. Chem. B106 9825

Frelink T, Visscher W and Van Veen J A R 1995 Surface Sci. 335353

Fujiwara N, Tsiakaras P and Stimming U 1999 J. Electroanal. Chem. 472120

Hogarth M P and Ralph T R 2002 Platinum Metals Review 46 146

Iwasita T 2002 Electrochim. Acta 473663

Iwasita T and Pastor E 1994 Electrochim. Acta 39 531, 547

Janssen M M P and Moolhuysen J 1977 J. Catal. 46289

Laborade H, Rezzouk A, Legér J -M, Lamy C, Srinivasan S, MacDonald D D and Khandkar A C (eds) 1994 J. Electrochem. Soc. 94275

Lamy C, Belgsir E M and Leger J M 2001 J. Appl. Electrochem. 31799

Lamy C, Lima A, Le Rhum V, Delime F, Contanceau C and Leger J-M 2002 J. Power Sources 105283

Li H, Sun G, Cao L, Jiang L and Xin Q 2007 Electrochim. Acta 526622

Liu Z, Ling X Y, Su X, Lee J Y and Gan L M 2005 J. Power Sources 1491

Mahmood T, Williams J O, Miles R and McNicol B D $1981 \mathrm{~J}$. Catal. 72218

McNicol B D and Short R T 1978 J. Electroanal. Chem. 92 115

O'Hayre R P, Cha S -W, Colella W and Prinz F B 2006 Fuel cell fundamentals (New York: John Wiley \& Sons, Inc)

Oliveria Neto A, Giz M J, Perez J, Ticianelli E A and Gonzalez E R 2002 J. Electrochem. Soc. 149 A272 
Pacheo V, Stantos D and Tremiliosi-Filho G Platinum/osmium as a catalyst for ethanol oxidation (http://www.Arofe.army. mil/conference/recent abstrac/200th meeting/symposia/hl/ 1051.pdf)

Rightmire R A, Rowlad R L, Boos D L and Beals D L $1964 J$. Electrochem. Soc. 111242

Spinace E V, Neto A O, Vasconcelos T R R and Linardi M 2004 J. Power Sources 13717

Song S Q et al 2005 Int. J. Hydrogen Energy 30995

Sugimoto W, Aoyama K, Kawaguchi T, Murakami Y and Takasu Y 2005 J. Electroanal. Chem. 576215
Vigier F, Coutanceau C, Perrard A, Belgsir E M and Lamy C 2004 J. Appl. Electrochem. 34439

Volkmar M S, Remo I, Elena P and Sergio G 1996 J. Phys. Chem. 10017901

Watanabe M and Motoo S 1975a Electroanal. Chem. \& Interf. Electrochem. $\mathbf{6 0} 267$

Watanabe M and Motoo S 1975b J. Electroanal. Chem. 60 275

Wasmus S and Kuver A 1999 J. Electroanal. Chem. 46114

Yang C et al 2001 Electrochem. Solid State Lett. 4 A31

Zhou W J et al 2004 J. Power Sources 131217 